\title{
Mapa mental das representações sociais de professores do ensino fundamental sobre a educação étnico-racial
}

\author{
Mental map of the social representations of the \\ teachers of the fundamental education \\ on the ethnic-racial education
}

Mapa mental de las representaciones sociales de maestros de la educación fundamental acerca de la educación étnico-racial

ANTÔNIO LUÍS PARLANDIN DOS SANTOS (iDa Glauber Ranieri Martins da Silva (id b ARLETE MARINHO GonÇALVES (iDc

\section{Resumo}

Este estudo teve como objetivo analisar a constituição das representações sociais de professores do ensino fundamental sobre educação étnico-racial e as implicações em sua prática pedagógica. Tem como referencial teórico metodológico a Teoria das Representações Sociais e traz como categorias fundamentais a "educação", "o racismo" e a "colonialidade". A abordagem é qualitativa, com Técnica de Evocação de Palavras para produção de dados pelos professores do ensino fundamental de uma escola pública e o Mapa Mental para sua análise. O percurso deste estudo nos conduz a uma visão psicossocial da educação para as relações étnico-raciais na atualidade. Problematizamos o cômodo lugar a que uma perspectiva hegemônica de ciência e

a Universidade Federal do Pará (UFPA), Belém, PA, Brasil. Doutor em Educação, e-mail: luisparlandinmarajo@gmail.com

b Universidade Federal do Pará (UFPA), Belém, PA, Brasil. Doutor em Educação, e-mail: glauberranieri@yahoo.com.br

c Universidade Federal do Pará (UFPA), Belém, PA, Brasil. Doutora em Educação, e-mail: arletmarinho@gmail.com 
pesquisa - moldada na história moderna/ocidental/eurocêntrica - nos levaria. Daí o problema deste estudo: Como se constituem as representações sociais de professores do ensino fundamental sobre a educação étnico-racial e quais as implicações em sua prática pedagógica? Os resultados revelam que as representações sociais dos professores do ensino fundamental sobre a educação étnico-racial - num contexto diferenciado de mudanças socioculturais, político-legais, econômicas e educacionais, engendrado desde o processo de redemocratização do Brasil - apresentam perspectivas ambíguas, que em alguns momentos podem reproduzir o racismo, 0 preconceito e discriminação racial via educação. Entretanto, além de mudanças sensíveis a visão, um "território simbólico" com "solo fértil" para que novas mudanças sejam concretizadas na sociedade e no cotidiano escolar vem sendo construído a partir de aproximações da perspectiva intercultural como referencial demandado pelos alunos e alunas e impulsionados pela organização e mobilização do Movimento Negro.

Palavras-chave: Representações sociais. Prática docente. Interculturalidade. Educação étnico-racial.

\begin{abstract}
This study aimed to analyze the constitution of social representations of elementary school teachers about ethnic-racial education and the implications for their pedagogical practice. It has the Theory of Social Representations as its theoretical and methodological reference and brings as fundamental categories "education", "racism" and "coloniality". The approach is qualitative, with the Technique of Evocation of Words for the production of data by the teachers of the elementary school of a public school and the Mental Map for its analysis. The course of this study leads us to a psychosocial view of education for ethnic-racial relations today. We question the comfortable place that a hegemonic perspective of science and research - shaped by modern / western / Eurocentric history - would take us. Hence the problem of this study: How are the social representations of elementary school teachers about ethnicracial education and what are the implications for their pedagogical practice? The results reveal that the social representations of elementary school teachers about ethnic-racial education - in a different context of socio-cultural, political-legal, economic and educational changes, engendered since the process of redemocratization in Brazil - present ambiguous perspectives, which in some moments can reproduce racism, prejudice and racial discrimination via education, but in addition to sensitive changes to the vision, a "symbolic territory" with "fertile soil" so that new changes can be realized in society and in school life has been built from approximations of the intercultural perspective as a reference demanded by male and female students and driven by the organization and mobilization of the Black Movement.
\end{abstract}

Keywords: Social representations. Teaching practice. Interculturality. Ethnic-racial education.

\title{
Resumen
}

Este estudio tuvo como objetivo analizar la constitución de las representaciones sociales de los maestros de primaria sobre la educación étnico-racial y las implicaciones 
para su práctica pedagógica. Tiene la Teoría de las representaciones sociales como referencia teórica y metodológica y trae como categorías fundamentales "educación", "racismo" y "colonialidad". El enfoque es cualitativo, con la Técnica de Evocación de Palabras para la producción de datos por parte de los docentes de la educación básica de una escuela pública y el Mapa Mental para su análisis. El curso de este estudio nos lleva a una visión psicosocial de la educación para las relaciones étnico-raciales de hoy. Cuestionamos el lugar cómodo al que nos llevaría una perspectiva hegemónica de la ciencia y la investigación, moldeada por la historia moderna / occidental / eurocéntrica. De ahí el problema de este estudio: ¿cómo son las representaciones sociales de los maestros de primaria sobre la educación étnico-racial y cuáles son las implicaciones para su práctica pedagógica? Los resultados revelan que las representaciones sociales de los maestros de primaria sobre la educación étnico-racial, en un contexto diferente de cambios socioculturales, político-legales, económicos y educativos, engendrados desde el proceso de redemocratización en Brasil, presentan perspectivas ambiguas, que en algunos Los momentos pueden reproducir el racismo, los prejuicios y la discriminación racial a través de la educación, pero además de los cambios sensibles a la visión, se ha construido un "territorio simbólico" con "suelo fértil" para que se puedan realizar nuevos cambios en la sociedad y en la vida escolar. aproximaciones de la perspectiva intercultural como referencia exigida por estudiantes y alumnas e impulsada por la organización y movilización del Movimiento Negro.

Palabras clave: representaciones sociales. Práctica docente. Interculturalidad Educación étnico-racial.

SAWABONA é uma forma de cumprimentar usada na África do Sul e quer dizer: "eu te respeito, eu te valorizo e tu és importante para mim". Como resposta as pessoas dizem: SHIKOBA, "Então eu existo para você" (TIMÓTEO, 2016, p. 1566).

\section{Introdução}

Sawabona a todos e todas — participantes e leitores — envolvidos com este estudo, que versa sobre a educação étnico-racial e objetiva analisar a constituição das representações sociais de professores do ensino fundamental sobre a educação étnico-racial e as implicações destas representações em suas práticas pedagógicas.

Sawabona e shikoba. Essas expressões nos encaminham a uma outra forma de pensar; marcam algo diferente de uma realidade construída com a elevação da lógica racional moderna a status de um conhecimento verdadeiro, que supostamente 
garantiria o acesso a um pretenso mundo civilizado, evoluído, superior. Mundo, na verdade, marcado historicamente pela devastação de povos, num intenso genocídio praticado desde a colonização europeia na América, Ásia e África, que de alguma forma continua a nos atingir...

É neste sentido que se faz importante o estudo das representações sociais de professores do ensino fundamental sobre a educação étnico-racial, base fundamental para a formação dos sujeitos em nossa sociedade. As representações sociais, de acordo com Moscovici (2015, p. 208), "são formadas através de influências recíprocas, através de negociações implícitas no curso das conversações, onde as pessoas se orientam para modelos simbólicos, imagens e valores compartilhados e específicos". Assim, para Martins da Silva e Nascimento (2019, p. 9), "as representações sociais emergem a partir das trocas e negociações de conhecimentos partilhados e consensuados entre os sujeitos de um grupo social.

Para compreendermos a perspectiva de estudo proposta é necessária uma compreensão da relação entre racismo, colonialidade e representações sociais que circulam no ambiente educacional. Portanto, faremos uma breve reflexão sobre essa relação.

Ao longo do século XIX, quando as ciências sociais adotaram uma lógica científica afinada com os métodos das ciências naturais, as ideias evolucionistas e funcionalistas predominavam no pensamento social. Assim, a história era configurada num plano linear em que as sociedades eram classificadas sob um padrão europeu de "evolução" e "civilização". Nesse sentido, as sociedades do além-mar eram consideradas primitivas e atrasadas e, portanto, só após percorrerem os mesmos percursos históricos dos países europeus poderiam alcançar o patamar da civilização, do racionalismo científico.

A razão iluminista, legitimada como uma filosofia de uma sociedade avançada, era a referência principal de estudos que se propunham a desvendar as relações sociais, tanto de teorias que se baseavam na integração social quanto em teorias que pretendiam ir além, de uma sociedade que sofreria mudanças radicais em seu modo de produção e alcançaria os patamares da igualdade, liberdade e 
Mapa mental das representações sociais de professores do ensino fundamental sobre a educação étnico-racial

fraternidade para além do sentido abstrato dos contratos sociais das sociedades burguesas (DOMINGUES, 2008).

Destacamos que, na contemporaneidade, tempo difícil, ambíguo e complexo, os paradoxos parecem saltar da realidade e denunciam os velhos problemas que assolam a humanidade: a persistência do racismo (hierarquização de grupos humanos com a finalidade de discriminá-los) nos remete a uma série de questionamentos e somos a cada dia desafiados a respondê-los para que uma espécie de conformismo e naturalização não apaguem, não camuflem, não silenciem, não abrandem o sofrimento que o racismo, o preconceito (concepção prévia irrefletida) e a discriminação (prática excludente) — formas de violência aterradoras — causam nos seres humanos em pleno século XXI.

O racismo é um fenômeno social que assola toda a sociedade e, em nossos discursos, aparenta ser um "mal" que precisa ser combatido, entretanto raramente reconhecemos que o praticamos: ele sempre é praticado por terceiros. $\mathrm{Na}$ escola, o reconhecimento da presença do racismo envolve tensões e paradoxos, porque é consenso que a escola é um local de formação do sujeito e não deve aniquilá-lo. Daí, percebemos que o fenômeno do racismo na escola nos demanda uma explicação a partir da problematização de como a educação pode combatê-lo.

A dificuldade de se trabalhar a questão do preconceito racial, no âmbito social e educacional, está ancorada na existência de um senso comum que, em geral, não reconhece a presença do racismo entre nós e, quando admite a sua realidade, sempre a situa nos outros. Ninguém se considera agente ativo de atitudes e comportamentos discriminatórios e racistas. Encontra-se, também bastante difundida a posição de que é melhor não problematizar o tema, pois assim poderemos estar estimulando o próprio racismo (SACAVINO et al., 2012, p. 24).

$\mathrm{Na}$ escola, escutamos o senso comum — sem inferiorizá-lo - e promovemos o diálogo com o conhecimento científico a fim de estudarmos o racismo numa perspectiva que não o reduz a um problema banal ou inexistente, silenciando-o.

Estamos diante de uma realidade em que a exclusão das diferenças permeia o processo de ensino-aprendizagem no ambiente escolar e o sistema de ensino tende a "pasteurizar as diferenças e padronizar os conteúdos e formas de ensinar", 
contribuindo para a perpetuação das desigualdades na sociedade (VENCATO, 2014, p. 39). Entretanto, a dinâmica social - complexa, contraditória, ambígua, "indomável" - não encerra um único pensar e fazer na escola, o que nos levou a estudar a educação para as relações étnico-raciais, partindo do senso comum, das representações daqueles que mediam o processo educacional escolar: os professores!

$\mathrm{Na}$ escola, por exemplo, o racismo se expressa nas relações entre os sujeitos que compõem a dinâmica social rotineira. Professores ainda reproduzem em suas práticas pedagógicas formas de preconceitos que se disseminam na sociedade em geral. Entretanto, os alunos e alunas hoje trazem inúmeras demandas socioculturais quando expressam suas diferenças na escola e os professores podem contribuir para superação de padrões de identidade e compreensões de mundo pautados em uma pureza racial inexistente, referenciada no modelo eurocêntrico de beleza, comportamento, valores, ideologias, que tenta forjar nos estudantes uma identidade marcada pela supremacia branca, cristã, heterossexual, masculina.

Arroyo (2012, p. 125), ao articular o campo de disputas políticas às representações que elaboramos acerca dos sujeitos e grupos que consideramos diferentes, evidencia que a educação e as teorias e práticas pedagógicas são também atravessadas e desafiadas pelas tensões e disputas sociais, sobretudo nos grupos subalternizados. Assim, pode-se abrir um espaço maior para que relações dialógicas se concretizem no cotidiano escolar, uma vez que, ao compreender a complexidade do processo de ensinar-aprender, os agentes escolares podem fazer frente à insistência do racismo na atualidade.

Nesse caso, ao articular o programa modernidade/colonialidade, a Teoria das Representações Sociais e a Educação intercultural nos remetem a investigações que englobam a realidade da educação escolar de uma perspectiva fundamental na construção do conhecimento, pois esta se encontra nas intersecções, pontes, travessas, "entre-lugares" (BHABHA, 2001), teias de significados que abarcam a relação dialógica entre indivíduo e sociedade. De acordo com Jovchelovitch (2011, p. 36):

A tarefa da representação nos campos sociais está relacionada à construção de visões de mundo, com o estabelecimento de sistemas de conhecimento cotidiano que não apenas buscam propor um referencial para guiar a comunicação, a coordenação da 
ação e a interpretação daquilo que está em questão, mas também expressam de forma efetiva os projetos e as identidades de atores sociais e as inter-relações que eles constroem.

As representações, portanto, num movimento dialógico com a realidade, a compõem e a transformam; guiam e são guiadas pela comunicação; traduzem e são traduzidas no que somos e nos tornamos, em interação com o outro que se enlaça em nossa identidade.

A partir desse pressuposto, a TRS não se limita a compreender um objeto particular, distante dos sujeitos envolvidos no processo de investigação; ela vai além para "captar" como o sujeito (indivíduo ou grupo) adquire uma capacidade de definição, uma função de identidade, sendo uma das formas como as representações expressam um valor simbólico. De acordo com Jodelet (2015, p. 317), a representação é uma "forma de conhecimento prático conectando um sujeito a um objeto"; caracterizar esse conhecimento como "prático" refere-se à "experiência a partir do qual ele é produzido, aos referenciais e condições em que ele é produzido e, sobretudo, ao fato de que a representação é empregada para agir no mundo dos outros".

Nesse sentido, as práticas pedagógicas podem ser analisadas criticamente com referenciais da educação intercultural para a construção de uma pedagogia antirracista a partir de sua dimensão que engendra significados imersos em redes de poder, expressos em discursos que legitimam determinadas representações sociais sobre a escola e tudo o que a constitui. Acerca da tensão entre os atores escolares e suas representações. A teoria das representações sociais, neste sentido,

[...] partilha o interesse em trazer à luz a estrutura das visões de mundo, das crenças e formas de vida que produzem teorias sobre o mundo, das crenças e formas de vida que produzem teorias sobre a vida cotidiana e os saberes que ela contém. Este saber é sempre plural, está profundamente ligado ao mundo da vida e à experiência vivida de uma comunidade, demarcando seus referenciais de pensamento, ação e relacionamento (JOVCHELOVITCH, 2011, p. 87).

Ao destacar a pluralidade dos saberes produzidos na vida cotidiana pelo senso comum, Jovchelovitch faz reverberar no campo científico uma nova 
perspectiva, de que os estudos precisam ponderar e abrir ou reforçar a abertura de um caminho diferente das assimetrias e desigualdades que se impõem em todos os âmbitos de nossa sociedade. Nascimento e Rodrigues (2018, p. 13) se reportam às representações sociais opondo-se à dicotomia histórica entre indivíduo e sociedade, situadas no cotidiano, na realidade que é produzida pelos sujeitos em interação e que é vivida conforme os sentidos que atribuímos às coisas, pessoas e experiências e que não separa conhecimento das emoções, paixões, sentimentos, enfim, da subjetividade e intersubjetividade inerentes a tudo que puder ser adjetivado como "humano", inclusive a produção científica. Nesse sentido, destacamos o problema deste estudo: Como se constituem as representações sociais de professores do ensino fundamental sobre a educação étnico-racial e quais as implicações em sua prática pedagógica?

Para dar conta destas reflexões traçamos os caminhos metodológicos a seguir.

\section{Metodologia}

Este estudo acerca das representações sociais de professores do ensino fundamental sobre a educação étnico-racial se configura no âmbito da abordagem qualitativa, que segundo Creswell (2010, p. 26) "é um meio para explorar e para entender o significado que os indivíduos ou os grupos atribuem a um problema social ou humano".

Os sujeitos do estudo foram selecionados a partir de critérios previamente estabelecidos: ser professor do ensino fundamental, estar atuando neste nível de ensino há pelo menos seis meses em escolas públicas, possuir nível superior, atuar em mais de uma escola.

Partindo destes critérios, selecionamos dez profissionais da educação, sendo todos brasileiros, paraenses de Belém, atuantes há mais de seis meses nas escolas públicas da capital paraense, sendo 6 (seis) do sexo feminino e 4 (quatro) do sexo masculino, com idades que variam de 28 anos a 59 anos.

Entre os aspectos relativos à autodeclaração étnica, cor/raça ou pertencimento étnico-racial, 5 (cinco) dos participantes declararam-se pardos(as), 3 (três) pretos(as), 1 (um) indígena e apenas um participante não declarou 
pertencimento étnico-racial. Vale destacar que nenhum dos participantes do estudo se declarou como branco.

Com relação à formação, 8 (oito) professores são graduados em pedagogia, 1 (uma) professora em Licenciatura em Letras e 1 (uma) em História. Todos os sujeitos atuam nos anos iniciais do ensino fundamental $\left(1^{\circ}\right.$ ao $5^{\circ}$ ano) há mais de cinco anos e trabalham há mais de seis meses em pelo menos duas escolas da rede pública de Belém.

Consideramos que os/as professores/as envolvidos neste estudo sobre representações sociais, enquanto atores sociais, falam do lugar que ocupam na teia social, imersos em um contexto específico com valores, crenças e ideologias partilhadas socialmente. A educação para as relações étnico-raciais, como processo que é caracterizado por determinadas práticas pedagógicas, provenientes das relações entre sujeitos diferentes, não é revelada de imediato no discurso dos professores, mas pode ser "extraída" por meio de técnicas que revelem o cerne do que pensam os atores acerca da questão étnico-racial na sociedade como um todo e nas escolas em particular.

Assim, o instrumento de coleta de dados foi a Técnica de Associação Livre de Palavras, que consiste em estimular os atores participantes para que digam o que pensam quando ouvem um termo (um ou mais estímulos indutores) que caracteriza o objeto da representação em estudo. O termo “evocação" como uma projeção mental significa o "ato de evocar", ou seja, trazer à lembrança, à imaginação algo que está presente na memória dos indivíduos (OLIVEIRA, 2007, p. 574).

Para tratamento e análise dos dados produzidos com a Técnica de Associação Livre de Palavras, trabalhamos com o "mapa mental”. De acordo com Hermann e Bovo (2005, p. 4), "Mapa Mental é essencialmente um diagrama hierarquizado de informações, no qual podemos facilmente identificar as relações e os vínculos entre as informações”.

$\mathrm{Na}$ etapa de interação com os participantes que contribuíram com a pesquisa, nos voltamos às seguintes variáveis sociodemográficas: nacionalidade, naturalidade, 
religião, gênero, idade, cor/raça/pertencimento étnico-racial, formação, disciplinas ministradas, séries em que lecionam e tempo de experiência profissional.

Foram essas pessoas que configuraram "os sentidos e a função simbólica" das temáticas deste estudo para que pudéssemos captar uma perspectiva psicossocial, de onde emergiram as representações sociais. De acordo com Jovchelovitch (2011, p. 37), a análise do sentido esclarece o fato de que diferentes pessoas, em diferentes contextos e tempos, produzem “outras" visões, símbolos e narrativas sobre o que é real, e assim podemos entender como diferentes representações se relacionam entre si e quais as consequências no mundo social.

\section{Mapa mental: educação étnico-racial para professores do ensino fundamental}

Conforme a Figura 1, a "educação para as relações étnico-raciais" e o "racismo" na escola geraram respectivamente as categorias: "formação", "barreiras", "ação pedagógica" e "ação transformadora/de resistência" e "barreira atitudinal". Representam o produto de uma interpretação sobre as evocações dos sujeitos da pesquisa, os quais procuraram elucidar os sentidos atribuídos às palavras evocadas e, assim, trazer evidências sobre os saberes que orientam suas práticas na escola.

Já a Figura 2 nos permite visualizar as objetivações que orientam as atitudes dos professores no cotidiano, nas relações que travam com alunos e outros professores. Explicita as representações sociais produzidas por eles sobre a educação ético-racial, consolidando o consenso produzido pelo grupo social participante do estudo. 
Mapa mental das representações sociais de professores do ensino fundamental sobre a

Figura 1 - Mapa Mental

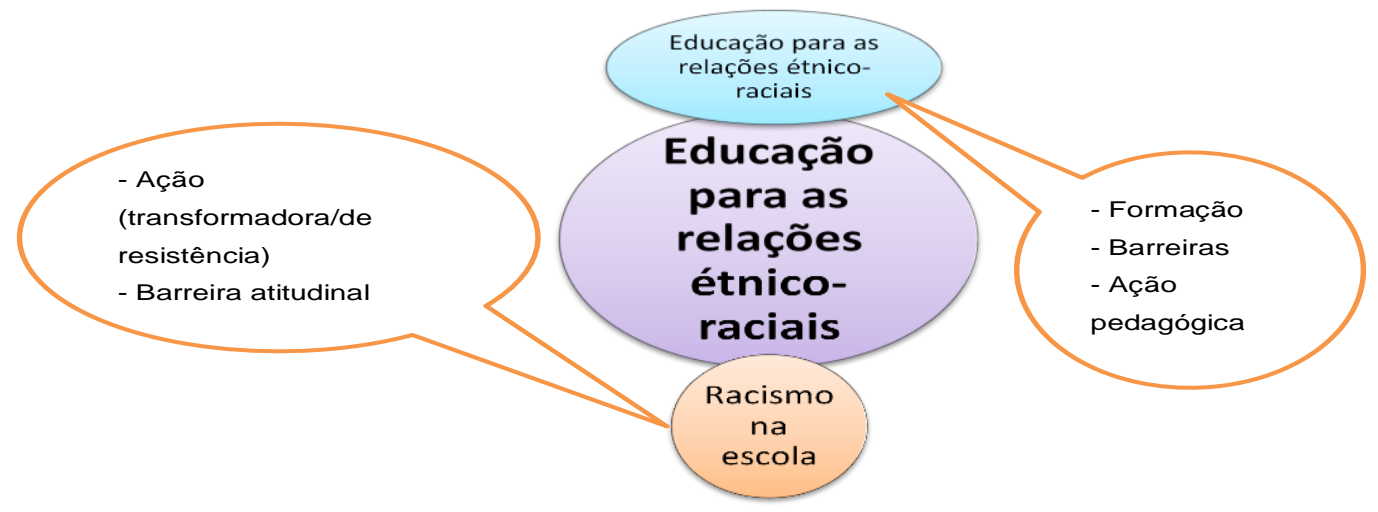

Fonte: Autores (2020).

Figura 2 - Objetivações que compõem as representações sociais de professores do ensino fundamental sobre a educação étnico-racial

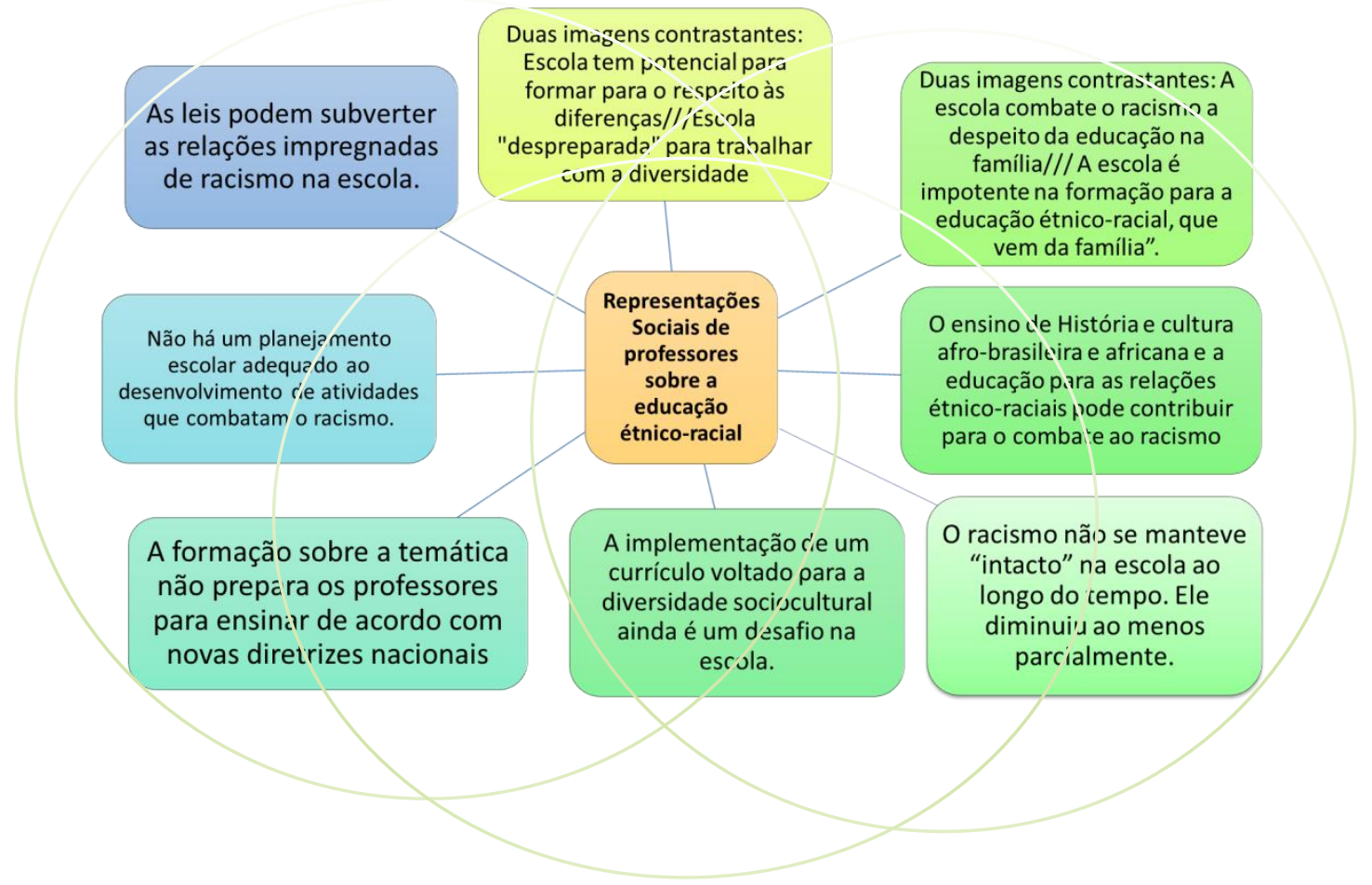

Fonte: Autores (2020).

A fim de subverter e intervir sobre as representações ligadas ao racismo, as quais perduram ainda hoje sobre a África e sobre a população negra do Brasil - e 
ainda sobre todo o legado — parte da história deste país - que contribui para a formação de todos nós, brasileiros, independentemente de raça/cor/etnia - a Lei $n^{\circ} 10.639 / 03$ estabelece a obrigatoriedade do ensino da cultura e história africana e afro-brasileira na educação básica e altera a Lei de Diretrizes e Bases da Educação Nacional (LDB - Lei no 9394/96).

Essa lei é fruto das lutas históricas do movimento negro e parte da necessidade de combater as desigualdades socioeconômicas e culturais que se espraiam na sociedade. As relações étnico-raciais no Brasil permeiam todas as instituições sociais e reverberam na escola, onde a complexidade da educação está na base de uma série de expectativas acerca do potencial transformador da educação escolar. Nesse contexto, vejamos as representações que os professores do ensino fundamental elaboraram acerca da educação étnico-racial e as tendências construídas a fim de orientar as práticas pedagógicas no cotidiano da escola.

\section{Racismo na escola: até quando?}

Embora a presença do racismo na escola seja amplamente admitida pelos professores do ensino fundamental participantes deste estudo, evidências de que sua manifestação nem sempre é percebida são comuns nos discursos dos depoentes. Nesse sentido, outro aspecto concorre para que o racismo seja naturalizado na escola: a ausência ou o trabalho parcial que resgatem a história e cultura africana, afro-brasileira e indígena nas práticas pedagógicas cotidianas da educação escolar. De acordo com Müller e Santos (2014, p. 95):

A escola no Brasil, nas práticas educativas, conteúdos curriculares e relações desenvolvidas em seus ambientes e entre aqueles que nele transitam, acaba reproduzindo uma "lógica de discriminação", fruto de uma hegemonia cultural de valorização da branquitude e desvalorização de padrões e valores culturais "não brancos". De modo particular, a cultura negra, fatos, personagens e suas contribuições na construção da sociedade brasileira são considerados de menor valor, e até mesmo invisibilizados, mantidos os estereótipos e preconceitos, representados nos livros didáticos e nos espaços escolares nas cenas de escravidão, sofrimento e subserviência $[\ldots]$. 
Portanto, como defende o autor, mais que admitir a presença do preconceito, da discriminação racial ou do racismo na escola, os professores - e todos aqueles que vivem os desafios impostos pela educação escolar — devem proceder uma radical transformação na perspectiva que considera a lógica de discriminação e orienta práticas perversas na escola.

$\mathrm{Na}$ categoria Barreira atitudinal, agregamos as palavras que remetem às manifestações do racismo na escola: "bullying, preconceito, desrespeito, intolerância, apelidos, egoísmo, ignorância, tristeza, violência, desamor, piadas, ignorância, dor, maldade, descaso, velado".

$\mathrm{Na}$ categoria Ação, agrupamos as palavras em torno de práticas que, segundo os professores, podem combater o racismo: "conversa, valorização, direitos, conhecimento, educação, formação, diálogo".

Os professores identificam a manifestação do racismo na escola, o caracterizam como velado ou manifesto de outras maneiras como nas piadas. Associam o racismo ao "bullying", que é uma expressão mais comum hoje para tratar da violência na escola, pelo maltrato sofrido por alunos e alunas que não se adequam a um padrão hegemônico de referência de beleza, classe, raça, gênero, etc. Ambas as categorias temáticas criadas — "Barreira atitudinal" e "Ação" evidenciam um movimento de reconhecimento da existência do racismo e das formas como podemos combatê-lo.

Nesse sentido, Müller e Santos (2014, p. 98) destacam o duplo e paradoxal papel da escola quando se reportam ao problema do racismo neste microespaço: "A escola pode reproduzir a sociedade como ela é, mas também pode transformá-la". Assim, diante do persistente racismo que assola o cotidiano escolar, com o mito da democracia racial ainda consolidando o preconceito e discriminação racial de forma velada e camuflada em "práticas aparentemente inclusivas, mas que mantêm a invisibilidade do negro", torna-se fundamental a "descolonização da prática pedagógica e a efetivação de uma pedagogia antirracista". De acordo com Gomes (2017, p. 49), 
[...] se queremos lutar contra o racismo, precisamos re-educar a nós mesmos, às nossas famílias, às escolas, às(aos) profissionais da educação, e à sociedade como um todo. Para isso, precisamos estudar, realizar pesquisas e compreender mais sobre a história da África e da cultura afro-brasileira e aprender a nos orgulhar da marcante, significante e respeitável ancestralidade africana no Brasil, compreendendo como esta se faz presente na vida e na história de negros, índios, brancos e amarelos brasileiros.

Para a autora, a primeira ação de luta contra o racismo é admiti-lo entre "nós", os professores, e nos reeducar para superá-lo. Construir outra perspectiva de relações étnico-raciais que nos fortifique para combater o preconceito, a discriminação racial e o racismo. Ela abarca os vários meios socioculturais e não reduz a luta à escola, que deve ser analisada em conjuntos com outras instituições.

A escola, nesse sentido, tem se apresentado como campo de tensão entre valores e práticas racistas e pela luta pelo combate às perspectivas inferiorizantes com imagens e sentidos que remetem a algo negativo - e/ou silenciamento da história e cultura afro-brasileira num contexto em que alunos e alunas demandam da escola a pluralidade tecida na convivência diária com a diferença/diversidade.

\section{Educação para as relações étnico-raciais: uma prática libertadora?}

A educação para as relações étnico-raciais, hoje, é preconizada por leis e diretrizes que respondem a demandas dos grupos socioculturais, os quais expressam a pluralidade da sociedade brasileira. De acordo com Brasil (2004, p. 31), a Educação das Relações Étnico-Raciais:

[...] tem por objetivo a divulgação e produção de conhecimentos, bem como de atitudes, posturas e valores que eduquem cidadãos quanto à pluralidade étnico-racial, tornando-os capazes de interagir e de negociar objetivos comuns que garantam, a todos, respeito aos direitos legais e valorização de identidade, na busca da consolidação da democracia brasileira.

Na mesma direção, Souza (2016, p. 72) considera a educação para as relações étnico-raciais como: uma "educação que valoriza e respeita outras culturas, em especial e neste caso, a africana e afro-brasileira, contribuindo para uma sociedade 
Mapa mental das representações sociais de professores do ensino fundamental sobre a educação étnico-racial

mais democrática em que a população negra brasileira possa exercer sua cidadania de forma mais plena".

Nesse sentido, entendemos a educação para as relações étnico-raciais como um processo atravessado por múltiplas dimensões, por valores, por questões legais, por fatores socioeconômicos. Portanto, um processo que suscita intenso esforço para ser concretizado no cotidiano escolar em articulação com os diferentes grupos socioculturais: seus saberes, práticas, dificuldades, concepções, desafios e identidades.

Observadas e pontuadas essas concepções, passemos a considerar a visão dos professores acerca da "educação para relações étnico-raciais": a partir dessa expressão, eles evocaram uma série de outras palavras que foram agrupadas nas seguintes categorias temáticas: 1) Barreiras, 2) Formação, 3) Ação pedagógica e 4) Dimensão valorativa.

$\mathrm{Na}$ categoria Barreiras, agregamos as palavras que remetem às dificuldades para efetivar uma "educação para as relações étnico-raciais": "preconceito" e "discriminação" (barreira atitudinal), "falta de infraestrutura" (barreira estrutural).

$\mathrm{Na}$ categoria Formação, agrupamos as palavras que remetem ao preparo do professor para efetivar uma educação para as relações étnico-raciais: “conhecimento, esclarecimento, formação, expressão, significados, transformação, professores, livros, escolas, aprendizado, identidade".

$\mathrm{Na}$ categoria Ação pedagógica, agregamos as palavras referentes às ações do professor em sala de aula para efetivar uma educação para as relações étnico-raciais: "ensino, prática, estratégia, metodologias, ações, discutir, diálogo, desenvolvimento".

$\mathrm{Na}$ categoria Dimensão valorativa, agregamos as palavras referentes às concepções e valores para efetivar uma educação para as relações étnico-raciais: "consciência, liberdade, responsabilidade, respeito, cidadania, valorização, compreensão, dedicação, comprometimento".

As temáticas produzidas pela sistematização das palavras evocadas e explicadas pelos professores participantes deste estudo nos levam a uma educação, a 
educação para as relações étnico-raciais, compreendida por múltiplas dimensões, num contínuo de proposições que revela a escola que temos hoje e a escola que precisa ser construída: Barreiras, Formação, Ação pedagógica e Dimensão valorativa nos trazem inúmeros aspectos relevantes para que as modificações sejam operadas desde a educação escolar com a finalidade de subverter os atuais problemas, como o racismo, que permeiam as relações étnico-raciais.

Consolida-se a imagem que retrata a superação do preconceito e discriminação raciais por meio da valorização da escola pela sociedade com a garantia da "infraestrutura" adequada para o trabalho do professor. Ao mesmo tempo, os professores enfatizam que as ações pedagógicas se transformarão à medida que tenham acesso a uma formação que lhes proporcione mais conhecimentos e esclarecimentos a fim de que outras mentalidades e identidades sejam originadas e se expressem na escola. Também há valores — individuais e coletivos — que entram na dinâmica das mudanças que retratariam a educação para as relações étnico-raciais expressas em ações pedagógicas diferenciadas.

Nesse sentido, a luta por uma educação de qualidade que atenda às necessidades efetivas da população foi formalmente incorporada na Constituição Federal (CF) de 1988, que traz a educação como um direito social: "Art. 205. A educação, direito de todos e dever do Estado e da família, será promovida e incentivada com a colaboração da sociedade, visando ao pleno desenvolvimento da pessoa, seu preparo para o exercício da cidadania e sua qualificação para o trabalho" (BRASIL, 1988).

A "cidadania" e a "dignidade da pessoa humana" são fundamentos da República Federativa do Brasil, que se constitui em Estado Democrático de Direito. Assim, tratar do "humano" significa considerar as diferenças que são construídas pelas culturas que formaram e fazem parte do que hoje é o país, assegurando minimamente o respeito à diversidade e sua valorização nos processos educacionais escolares e não escolares.

Nesse sentido, as Diretrizes Curriculares Nacionais da Educação Básica (BRASIL, 2013, p. 16, grifo nosso) concebem a educação como o: “[...] o processo 
Mapa mental das representações sociais de professores do ensino fundamental sobre a educação étnico-racial

de socialização da cultura da vida, no qual se constroem, se mantêm e se transformam saberes, conhecimentos e valores".

Trata-se, portanto, da educação como processo de socialização em que há a "manutenção" e "transformação" — de saberes, conhecimentos e valores — como processos que trazem a relevância da diversidade, e não a reprodução de preconceitos, discriminação e racismo na escola. Nesse sentido, as lutas dos movimentos populares, como o Movimento Negro, têm enfatizado o racismo velado que se espraia nas instituições sociais, inclusive na escola. Consequente a essa luta, mudanças legais são barganhadas e novas leis são criadas, como a Lei no 10.639 de 9 de janeiro de 2003 e posteriormente a Lei no 11.645 de 10 de março de 2008, que modificou a LDB: "S 2 o Os conteúdos referentes à história e cultura afro-brasileira e dos povos indígenas brasileiros serão ministrados no âmbito de todo o currículo escolar [...]”.

Não se trata, pois, da criação de uma nova disciplina, mas da inclusão da história e cultura africana e afro-brasileira e indígena na formação integral do educando, contemplando as múltiplas dimensões sociais da problemática do racismo no Brasil. Considerar todo o currículo escolar, assim, significa envolver as práticas pedagógicas dos professores das diversas disciplinas de forma articulada no cotidiano escolar: não são momentos isolados e esporádicos na formação do educando. De acordo com Müller e Santos (2014, p. 93):

Quanto ao patrimônio cultural afro-brasileiro, é através do cotidiano escolar que se conhecem muitas produções afro-brasileiras que escapam ao conhecimento da sociedade. É a escola que permite, muitas vezes, que práticas, valores e conteúdos culturais permaneçam vivos, bem como sejam transmitidos e preservados (e até mesmo ressignificados), tecendo outros conhecimentos.

A educação escolar tem, segundo os autores, papel fundamental na divulgação das produções afro-brasileiras para toda a sociedade, permitindo que práticas, valores e conteúdos culturais sejam "reatualizados" e se propaguem entre aqueles que possuem ascendência africana ou não. Entretanto, de acordo com Ribeiro e Santos (2016, p. 53), o conhecimento ocidentalizado foi construído segundo uma lógica em que: 
[...] teorias, saberes e experiências dos subalternos - povos colonizados - são postos em segundo plano, muitas vezes deslegitimados, em detrimento dos saberes eurocentrados canonizados, formadores dos tropos que compõem a tradição filosófica racionalista dessa parte do mundo.

Trata-se de uma "construção intelectual marginalizada" pejorativamente rotulada de "saber local". Os autores ainda consideram que há uma tensão entre "forças" que intentam "perpetuar a supremacia de uma estrutura ideológica e histórica espaço-temporal" (p. 53) e movimentos que lutam pela transformação da realidade por meio de "novas maneiras de ser, sentir e saber o mundo".

Nesse contexto, emerge a Lei $\mathrm{n}^{\mathrm{o}} 10.639 / 03$, enquanto uma das maiores conquistas do Movimento Negro, figurando-se como um imperativo que reivindica um revisionismo acerca da História do povo negro no Brasil e sua participação na construção da nação. É a quebra "pós-colonial" nas tramas, enredos e cronologias de uma História do Brasil eurocentrada (RIBEIRO; SANTOS, 2016, p. 54).

Esta lei tem, segundo os autores, "potencial fecundo" para (re)escrever narrativas acerca da temática da história e cultura africana e afro-brasileira. Um dos desafios é superar uma visão monocultural de mundo, religando passado e presente de forma crítico-reflexiva, para enfim subverter a longa tradição — que ainda faz parte e é predominante no cotidiano da educação escolar — de se conceber e ensinar a história como "mera compilação de fatos "verdadeiros", repercutindo numa percepção conteudista. Candau (2016, p. 807, grifo nosso) defende a "reinvenção da escola":

Não acreditamos na padronização, em currículos únicos e engessados e perspectivas que reduzem o direito à educação a resultados uniformes. Acreditamos no potencial dos educadores para construir propostas educativas coletivas e plurais. É tempo de inovar, atrever-se a realizar experiências pedagógicas a partir de paradigmas educacionais "outros", mobilizar as comunidades educativas na construção de projetos político-pedagógicos relevantes para cada contexto. Nesse horizonte, a perspectiva intercultural pode oferecer contribuições especialmente relevantes.

A perspectiva intercultural, para a autora, ao enfatizar "propostas educativas coletivas e plurais", contribui para que os professores repensem representações, concepções, crenças, opiniões, ações, atitudes, conteúdos e práticas, opondo-se veementemente contra a padronização/homogeneização do quê ou de quem não 
pode ser mutilado com nenhum tipo de violência simbólica: os alunos e alunas partícipes da educação escolar.

Os desafios da educação escolar são inúmeros neste início de século. A dinâmica sociocultural da sociedade e da escola "exigem" que todos e todas se envolvam nos processos de mudança, a qual não será conquistada com a reprodução de relações étnico-raciais pautadas no racismo, na intolerância, na segregação do outro que não consegue se adequar ao padrão de saber e de ser considerado referência.

\section{Considerações finais}

O percurso deste estudo nos conduz a uma visão psicossocial da educação para as relações étnico-raciais na atualidade. Ao situar o sujeito em um contexto sociocultural, negamos o conhecimento sem "alma", abstrato, pretensamente imparcial, neutro, "puro", ao mesmo tempo em que lutamos para resgatar os conhecimentos que entrelaçam subjetividade, intersubjetividade e transubjetividade.

Nesse sentido, as representações sociais de professores do ensino fundamental sobre a educação para as relações étnico-raciais emergiram de um amplo movimento — consolidado nas relações engendradas pelos professores que revelou a dinâmica com que são formadas - pelos processos de objetivação e ancoragem - as representações sociais e as consequentes atitudes que surgem no "horizonte" de saberes, expressando contradições e ambiguidades, imagens e sentidos que configuram a dinâmica da realidade sociocultural.

As relações tecidas no cotidiano e representadas nos discursos dos professores trazem as marcas da sociedade em que são formadas, mas deixam evidentes também as transformações concretizadas desde a expressão simbólica, criativa, com redefinições que, às vezes, "rasgam" imagens e sentidos que padrões hegemônicos insistem em propagar como verdades absolutas. Uma certa mudança, entretanto, num nível mais subjetivo - mesmo que orientado por um "horizonte" coletivo de debates, divulgações, desnaturalizações acerca do racismo — poderá não 
corresponder às expectativas de uma mudança mais global/radical como a legislação sobre a temática dita.

\section{Referências}

ARROYO, M. G. Outros sujeitos, outras pedagogias. Petrópolis, RJ: Vozes: 2012.

BHABHA, H. O Local da Cultura. Belo Horizonte: Editora UFMG, 2001.

BRASIL. Secretaria de Educação Continuada, Alfabetização, Diversidade e Inclusão. Diretrizes Curriculares Nacionais da Educação Básica. MEC/CNE. Brasília, 2013.BRASIL. Constituição (1988). Constituição da República Federativa do Brasil. Brasília, DF: Senado, 1988.

BRASIL. Conselho Nacional de Educação (CNE). Parecer do Conselho Nacional de Educaşão Câmara Plena (CNE/CP) n³, de 10 de margo de 2004. Institui as Diretrizes Curriculares Nacionais para a Educação das Relações Étnico-Raciais e para o Ensino de História e Cultura AfroBrasileira e Africana. Disponível em: http://portal.mec.gov.br/cne/arquivos/pdf/003.pdf. Acesso em: 11 abr. 2020.

BRASIL. Lei no 9.394, de 20 de dezembro de 1996. Estabelece as diretrizes e bases da educação nacional. Disponível em: http://www.planalto.gov.br/ccivil_03/LEIS/19394.htm. Acesso em: 15 mar. 2020.

BRASIL. Lei n 10.639 de 9 de janeiro de 2003. Altera a Lei no 9.394/1996, que estabelece as diretrizes e bases da educação nacional, para incluir no currículo oficial da Rede de Ensino a obrigatoriedade da temática "História e Cultura Afro-brasileira", e dá outras providências. Diário Oficial da República Federativa do Brasil. Brasília, DF, 9 jan. 2003.

CANDAU, V. M. F. Cotidiano escolar e práticas interculturais. Cadernos de Pesquisa, v. 46, n. 161, p. 802-820, jul./set. 2016.

CRESWELL, J. W. Projeto de pesquisa: métodos qualitativo, quantitativo e misto. Trad. Magda Lopes. 3. ed. Porto Alegre: ARTMED, 2010.

DOMINGUES, J. M. Teorias Sociológicas no Século XX. 3 ed. Rio de Janeiro: Civilização Brasileira, 2008.

GOMES, N. L. Alguns termos e conceitos presentes no debate sobre relações raciais no Brasil: uma breve discussão. In: BRASIL. Educação Antirracista: caminhos abertos pela Lei federal n ${ }^{\circ}$ 10.639/03. Brasília: MEC, Secretaria de educação continuada e alfabetização e diversidade, 2017. p. 39-62.

HERMANN, W.; BOVO, V. Mapas Mentais: Enriquecendo Inteligências Manual de Aprendizagem e Desenvolvimento de Inteligências: captação, seleção, organização, síntese, criação e gerenciamento de conhecimentos. Campinas: [s.n.], 2005. Disponível em: http://www.idph.net/download/intrommentais.pdf. Acesso em: 20 mar. 2020.

JODELET, D. Problemáticas psicossociais da abordagem da noção de sujeito. Cadernos de Pesquisa, v. 45, n. 156, p. 314-327, abr./jun. 2015. 
Mapa mental das representações sociais de professores do ensino fundamental sobre a educação étnico-racial

JOVCHELOVITCH, S. Os contextos do saber: representações, comunidade e cultura. Petrópolis, RJ: Vozes, 2011.

MARTINS DA SILVA, G. R.; NASCIMENTO, I. P. O que dizem os professores indígenas Tembé sobre a educação escolar e o futuro da aldeia. Revista Educação em Questão, v. 57, n. 54, 29 nov. 2019.

MOSCOVICI, S. Representações sociais: investigações em psicologia social. 11. ed. Petrópolis, RJ: Vozes, 2015.

MÜLLER, T. M. P.; SANTOS, J. L. R. A presença/ausência da história e cultura negra na escola. In: MÜLLER, T. M. P.; COELHO, W. N. B. (orgs.). Relações étnico-raciais e diversidade. Niterói: Editora da UFF; Alternativa, 2014. p. 87-100.

NASCIMENTO, I. P.; RODRIGUES, S. E. C. Representações sociais sobre a permanência na docência: o que dizem docentes do ensino fundamental? Educação em Pesquisa, São Paulo, v. 44, e166148, 2018.

OLIVEIRA, D. C. et al. Análise das evocações livres: uma técnica de análise estrutural das representações sociais. In: MOREIRA, A. S. P.; CAMARGO, B. V. (orgs.). Contribuições para a teoria e o método de estudos das representações sociais. João Pessoa: EdUFPB, 2007.

RIBEIRO, R. R.; SANTOS, A. J. S. O caráter acontecimental da Lei n. 10.639/03: o desafio de (re) escrever narrativas sobre a história africana e afro-brasileira sob um novo contexto epistemológico e histórico. In.: COELHO, W. N. B.; SILVA, C. A. F.; SOARES, N. J. B. (orgs.). A diversidade em discussão. São Paulo: Editora da Física, 2016. p. 51-91.

SACAVINO, S. B. et al. Educação, preconceito e discriminação. In: CANDAU, V. M. F. (org.). Somos todos iguais? Escola, discriminação e educação em direitos humanos. 2. ed. Rio de Janeiro: Lamparina, 2012.

SOUZA, M. E. V. Educação para as Relações Étnico-raciais e Interculturalidade: desafios contemporâneos. In: COELHO, W. N. B.; OLIVEIRA, J. M. Estudos sobre relaçoes étnicoraciais e educação no Brasil. São Paulo: Editora e Livraria da Física, 2016. p. 71-88.

TIMÓTEO, S. M. Sawabona shikoba — “eu sou bom”. Revista Jurídica Luso-Brasileira, ano 2, n. 1, 2016.

VENCATO, A. P. Diferenças na escola. In: MISKOLCI, R.; LEITE JÚNIOR, J. Diferenças na educação: outros aprendizados. São Carlos: EdUFSCar, 2014. p. 20-56.

RECEBIDO: 01/06/2020

APROVADO: $28 / 07 / 2020$

RECEIVED:06/01/2020

APPROVED: 07/28/2020

RECIBIDO: 01/06/2020

APROBADO: 28/07/2020 